\title{
Dynamic mapping of flood boundaries: current possibilities offered by Earth Observation System and Cellular Automata
}

\author{
A. Gerardi, M. Ioannilli, and F. Del Frate \\ Earth Observation Laboratory, Department of Civil Engineering and Computer Science, \\ Tor Vergata University, via del Politecnico 1, 00133 Rome, Italy \\ Received: 12 November 2013 - Accepted: 5 December 2013 - Published: 16 January 2014 \\ Correspondence to: A. Gerardi (gerardi_andre79@ hotmail.com) \\ Published by Copernicus Publications on behalf of the European Geosciences Union.
}

\begin{abstract}
Flooding is an ongoing and complex problem in Italy. Very large floods caused inundation of the closest areas to the city centre in Rome in 1937, 1976, 1992, 2005 and most recently in 2008. Rome is located at the bottom of the Tiber River catchment, which 5 cover an area of $16000 \mathrm{~km}^{2}$. Intense precipitations struck the Tyrrhenian Sea side of the peninsula inducing a flood event on the Tiber and Aniene's (Tiber's tributary) basins - which captured the attention of the national and international media. Actually there is no validated model in operation for real-time flood forecasting. This research aims at comparing the Cellular Model CAESAR (Cellular Automation Evolutionary Slope And

10 River) application on a reach of the Aniene River with Earth Observation Systems. The main result expected is the prediction of future channel dynamics on short and medium time scale.
\end{abstract}

\section{Introduction}

The scope of geomorphology, which has an intermediate position, almost a connec15 tion, between physical geography and geology as described in Castiglioni (1982), is the study and interpretation of the terrestrial morphology. In particular fluvial geomorphology, a sub-discipline of geomorphology, aims at the knowledge and interpretation of fluvial processes creating and modifing landforms as reported in Marchetti (2000), and, to this purpose, investigates, at different time scale, both the production

20 processes, flow and storage of sediment in a river basin and the forms resulting in the river bed and floodplain, as in Newson and Sear (1993). The study of river systems, for its own complexity, requires the adoption of methodology and techniques that usually differ from each other according to the application field. Among the tools adopted in fluvial geomorphology in recent years, the application of numerical mathematical models is gaining increasing attention. Such tools allow to simulate the behavior of fluvial units particularly interesting, predicting the possible routing of the water bodies due to 
several stress. In this way, using observations at multiple space (individual morphological unit, line, basin) and time (from a single hydrological event to thousands years) scales, it is possible to explore and better understand the relations connecting the variables driving geomorphological processes. This article focuses on a particular type

5 of numerical models, the so called "cellular" models, developed for gravel-bed rivers (rivers with gravelly beds), with braided morphology (interlaced channels) or wandering behavior (transitional). In particular, the research identifies the application to the Aniene basin of CAESAR (Cellular Automation Evolutionary Slope And River) the cellular model developed in 1996 by Prof. Coulthard (Hull University, UK), comparing the

- results with Earth Observation Systems data.

\section{State of the art}

In 1993, in a work of literature review, Ferguson noted that a relatively small number of numerical models has been developed for the application to braided bed. In the last $15 \mathrm{yr}$, this situation has really changed and amazing progresses have been made in

15 modelling a wide range of scales, as in Nicholas (2005). Two-dimensional and threedimensional Computational Fluid Dynamic (CFD) Models, has been applied both to the study of fluid dynamics associated with individual morphological units and to the hydro morphological survey as fully described in Lane et al. (1999); Formann et al. (2007); $\mathrm{Li}$ et al. (2008); Montoya Cardona (2008). Associating some numerical techniques,

20 simulating sediment transport and modification of river bed, to the strictly hydraulic calculation modules generating assessment of river channels evolution trends, as well as quantification details of the sediment budget, is also fully described in Li et al. (2008). Up to now, however, the predictive power is limited by several factors:

- computing power required;

25 - amount and accuracy of data input;

- need of simplifying assumptions for the modeling process of sediment transport; 835

- data calibration and results validation are very difficult due to monitoring problematic and variables modeling.

These limitations have led to the development of an alternative model known as "Reduced Complexity Model" (RCM), which basically can reduce the conceptual 5 complexity. Thanks to effective simplification of concepts introduced to reproduce the various physical processes, RCM ensures substantially increased calculation speed, allowing applications to river stretches of considerable size and for longer time scales, unthinkable for any CFD (1-10-100 yr). Among RCM, the so called "cellular" numerical models, (Cellular Model, CM), have been introduced since the early 1990s; fur10 ther improvements in Cellular Models are considered the most important step in fluvial geomorphological analysis in the last $15 \mathrm{yr}$, as in Nicholas (2005). The first of these models, legitimately considered the forerunners of $\mathrm{CM}$, was designed by Murray and Paola in 1994, fully described in Murray and Paola (1994, 1997, 2003). Their model (MP) simulated the evolution of a braided river through the application of simplified 15 sediments transport rules among contiguous cells, as a function only of the flow rate of the liquid in transit and of the gradient among cells. Applying the so called "Cellular Automata" scheme, as in Wolfram (1984), adapted as necessary, the MP has shown to be capable of recreating the processes of divergence and convergence of the flow, and of lateral migration towards downstream of bars and channels. Murray and Paola,

20 in essence, reproduced macro-conditions that govern the settings of a braided channel morphology: not limited and sliding sideways flows that produce bottom and sides erosion, simplifying physical laws that underlie this phenomenon, as in Coulthard et al. (2008). Their model was the first to have revealed that it was not necessary to follow a "reductionist" modeling approach that tries to simulate each operating process in great

25 detail. Through their work it is now a widespread belief that a qualitative understanding with adequate details, is preferable to a quantitative solution. 
Murray and Paola's model has inspired the development of a series of similar CM. After the development of a basin evolution LEM (Landscape Evolution Model), Coulthard continued in the refinement of the same model, adapted for applications in river beds,

5 of any morphology, as described in Coulthard et al. (2000, 2002, 2007), Coulthard et al. (2008), Coulthard (2006), and Van De Wiel et al. (2007). His model was built editing the MP routing scheme: he honed modules calculation of tie rods for water and sediment, and developed algorithms for process simulation of bank erosion and transport in suspension. The Coulthard's model, called CAESAR (Cellular Automation Evolutionary

10 Slope And River Model) was applied to river stretches from 4 to $40 \mathrm{~km}$, with a cell size of calculation variables from $2 \mathrm{~m} \times 2 \mathrm{~m}$, up to $50 \mathrm{~m} \times 50 \mathrm{~m}$. Used in reach mode (a section of the river), the model requires several input data: the starting DEM, the values of both solid and liquid flow in input from upstream, particle size, characterization of the background texture and the possible vegetation cover. For each cell of the calcu-

15 lation model it associates a dimension value, the liquid flow, specific particle size, the vegetation cover and the thickness of the erodible riverbed. CAESAR implements an iterative process of "scanning" updating the set of values associated with each cell, by the application of all the rules that govern the simplified individual processes. Generally we can distinguish 5 sets of rules:

20 1. hydraulic - it regulates the distribution of liquid flow;

2. fluvial erosion and deposition - for modelling the bed load transport in suspension as reported in Wilcock and Crowe (2003) and Einstein (1950);

3. bank erosion - it defines the processes of retraction of river banks only for cells close to the active edge of the riverbed;

4. hydrological - it regulates the conversion inflows-outflows adopting TOPMODEL as basic scheme as in Beven and Kirkby (1979);

837

5. slope processes (mass movement, creep) - it models the handling of the collapsing soil or creep from the slopes.

CAESAR, applied in reach mode, implements only the cellular automation of liquid components (1), sediment transport (2), and lateral erosion (3). For each iteration 5 CAESAR changes the values of the cell analyzed, during the previous time step, in accordance with the set of rules listed above and with the property values of neighboring cells. This means that the total amount of erosion of a cell depends on the water head on that cell and by the slope between the same cells and the adjacent ones. CAESAR can work both in basin scale and in riverbed scale; the input needed for a basin 10 scale analysis is the hourly rain, constant throughout the basin which then becomes flow according to the rainfall-runoff TOPMODEL modified model as shown in Fig. 1.

Wishing to use CAESAR for a section-scale, the input required by the model is the flow rate (solid and liquid). For each scan (scanning and updating the values of all cells in a given area for a given time step) the hydraulic flow (both in riverbed scale and 15 in basin scale) is directed to the three cells hydraulically lower but, if the total water flow is greater than the subsurface flow, the excess is treated as runoff and its swing is evaluated through an +adaptation of the Manning's equation as shown in Eq. (1):

$Q=U A=\left(h^{2 / 3} \sqrt{S} A\right)$

where $Q, U$ and $h$ represent respectively the flow rate, the flow velocity and the water 20 head, $A$ is the area of the cross section of the flow, $S$ is the slope. For cells interested, a sash evaluation is obtained through the equation reported in Wilcock and Crowe (2003), applied to eleven different granulometric fractions (1 to $256 \mathrm{~mm}$ ) that defines the particle size of the riverbed, in turn divided into a series of 10 active layers, according to Hoey and Ferguson (1994). Depending on the size, the different clusters

25 are transported both as load and as suspended bottom sediments, determining the creation of an "armored" surface and a stratification of the bed. When simulations are very long, it is necessary to be sure that the finer sediments are deposited in order 
to consider the real resources for the next erosion process. The main "engine" of the model, responsible for morphological modifications occurring in the riverbed, is related to the processes of pick-up, transport and sedimentation of materials. The transport process is driven by a "mixed-size" formula, which calculates the shipping rate for each

5 ith particle size fraction of the sediments through the Wilcock and Crowe's equation as shown in Eq. (2):

$q_{i}=\frac{F_{i} U^{3} W_{i}^{*}}{(s-i) g}$

where $F_{i}$ is the volume fraction of the $i$ th granulometric class into active layer, $U$ is the shear velocity, $s$ is the relationship between the sediment and water, $g$ is the gravita10 tional constant and $W_{i}^{*}$ is a complex function that relates the transport rate of the sieve fraction with total transport rate. Actually, there are also rules in the code for the slope processes. These types of processes are limited to movements of mass, when a given inclination value is exceeded, together with soil creep phenomena. The material enters the river system from the side (in order to simulate phenomena as border collapse).

15 Once the rate of erosion/sedimentation is calculated, it is possible to update the values of height and size for each cell of the area modeled. One of the most innovative aspects of CAESAR is certainly the use of a variable "time step". The cellular automation models apply for each iteration, a temporal upgrade of the cells values with a series of rules or equations as shown in Fig. 2; for each iteration CAESAR uses a time step that 20 varies as a function of the maximum amount of erosion or sedimentation ensuring that this value does not exceed never $10 \%$ of the local slope. In this way it prevents any computational instability that can lead to a non-realistic evolution of territory.

The user can set a parameter (erodelimit), which represents the maximum amount of eroded or deposited material is greater than the value of erode-limit, then the model

25 halves the time step and repeats the calculation until that value is below the limit. In this way we can check any computational instability, because it is never involved an excessive amount of eroded and deposited material, allowing the model to have long 839

time steps (up to $1 \mathrm{~h}$ ) in periods of quiescence (e.g. low flow) but also short time steps (up to a tenth of a second) during periods of high flow rates or strong erosion activity. An important feature is also presented by the resolution and the cell size of DEM. The erodelimit parameter depends on the size of cells, because the variation in the height

5 of the cells involves changes in local slopes. An increase in size of $0.1 \mathrm{~m}$ for a cell belonging to a grid of $1 \mathrm{~m}$ size determines, with respect to neighboring unchanged cells, an increasing of $10 \%$ in slope. Instead, if the cell size is $10 \mathrm{~m}$, the change is only $1 \%$. Therefore, for cells of greater size, the changes between the cells are less severe in altering the slopes. This indicates that the choice of the value of erodelimit must

10 be made consciously by the user, as a cell size function. The problem of resolution is related to the duration of the simulation: a single flood event simulated with high temporal resolution and high spatial resolution (number of cells higher to 500000 ), may take a whole day for processing.

\section{Simulation model}

15 The simulation of the water flow propagation is based on a deeply knowledge of the model that is the basis of the physical phenomenon. Such kind of knowledge is fully integrated in TOPMODEL, as described in Beven and Kirkby (1979), which requires a Digital Elevation Model, the rainfall sequence and potential evapotranspiration data, as input. TOPMODEL is widely used for its efficiency in reproducing hydrological phenomena manipulating DEM. Refer to Beven and Kirkby (1979); Beven and Wood (1983); Beven (1995) for a theoretical description on which TOPMODEL is based and in this section for a better analysis of the structure of the model as showed in Fig. 3.

As discussed in Quinn et al. (1997), TOPMODEL requires the determination of a topographic index calculated as shown in Eq. (3):

$25 \ln \left(\frac{a}{\tan (b)}\right)$ 
in which a represents the cumulative area drained through a unit length of contour line and $\tan (b)$ is the slope. As mentioned above, TOPMODEL is widely used for an accurate simulation of hydrological processes over the entire watershed scale. Assuming the presence of a water body with a pronounced slope and a saturated flow parallel 5 to the local surface $\tan (b)$, it can be possible to evaluate the down slope saturated subsurface flow rate $q_{i}$ per unit contour length $\left(\frac{m^{2}}{h}\right)$ as described by the Eq. (4):

$q_{i}=T_{0} \tan \left[b_{i} e\left(\frac{-S_{i}}{m}\right)\right]$

with the assumption of an homogeneous soil, $T_{0}$ is the average soil transmissivity, $b_{i}$ is the slope angle, $S_{i}$ is the local storage deficit and $m$ expresses the increase of the 10 transmissivity with depth. With these assumptions, the local deficit can be derived as shown in Eq. (5):

$S_{i}=S^{*}+m\left\{\lambda-\ln \left[\frac{a}{\tan (b)}\right]_{i}\right\}$

in which $S^{*}$ is the average storage deficit and $\lambda$ is the areal average of $\ln \left[\frac{a}{\tan (b)}\right]_{i}$. The latest equation is fundamentally relevant in the determination of saturated areas at 15 each cycle time. More in depth, $S_{i}$ can assume both positive and negative values. In the first case the area is not saturated while negative values indicate that the saturated area determines the overland propagation of a water body. Further explanations regarding not saturated areas evaluation, vertical flow, evapotranspiration and flow routing related to saturated areas can be found in Beven et al. (1995).

\section{5 CAESAR case study: Aniene River}

The CAESAR model has a routine allowing the side-evolution, and then it can simulate the evolution of a meandering river, as well as a braided river, as in Coulthard (2006).

The results obtained in the simulations were satisfactory, as they showed how the erosion side can be simulated in a model of CA (Cellular Automata). The outer edges of the meanders have been eroded in larger amounts in correspondence of the tighter corners. To simulate the sedimentation and the redistribution of sediments in the chan-

5 nels, an algorithm that calculates the radius of curvature of local meander was used. The increased erosion in external shores has been measured precisely through the value of the radius of curvature of the meander. Although there are potential improvements of the model for studying meandering rivers, CAESAR is also demonstrating its potential with these types of riverbeds. In a further application, the same patterns have

0 been appropriately modified both to simulate the placing on the bed of large amounts of sediment coming from the side and to simulate, as in De Rosa (2008), the effects of a gravitative process that interferes with the river bed, blocking it partially or totally. The basin of the Aniene River lies to the east of Rome, up to the Lazio Region border, over an area of 1400 square kilometers, or for an extension equal to $9 \%$ of that of the Tiber basin to which it contributes, in terms of instantaneous flow rates, in a percentage significantly greater. The Aniene basin can be essentially considered divided into two distinct parts both from morphological and socio-economic point of view. In fact, the bed and the basin up to Tivoli have morphologically typical characteristic of mountain watercourses, while downstream characteristics are typical of lowland rivers.

20 The settlements are also affected by that division: an essentially mountain-agricultural in the high basin, an industrial economy in the lower basin. In the last part, from Tivoli to the confluence with the Tiber, the Aniene River flows through one flood plain, whose territory is made up of blankets and volcanic travertine with some outcrops, where we can verify the flooding of the Aniene River. The Aniene River enters the city of Rome

25 through the industrial Tiburtina area. The lean bed is subject to obstructions resulting from natural (Lunghezza and Tor Cervara) and artificial (Ponte Lucano Vecchio, Ponte FF.SS. in Lunghezza, Ponte di Tor Cervara, Ponte Mammolo Vecchio, Ponte Nomentano, Ponte Salario Vecchio) bottlenecks as shown in Fig. 4 and sometimes with border vegetation collapsed into the lean river. The border banks of the lean riverbed are 
subject, in such parts, to instability phenomena for landslide erosion. Recent studies, as described in Surian et al. $(2008,2009 a, b)$, have shown that impressive concordances and some specific exceptions in the behaviour of these watercourses, may constitute a group sufficiently representative of the changes undergone by most of the main Italian

5 rivers. Various forms of human intervention have affected the water courses, with different impacts and timing, but substantially with similar morphological manifestations. Sewer, sediment extraction, dams construction, reforestation, have changed, directly or indirectly, the morphological dynamics in all these contexts. In many cases the embankments construction or repellents bank began at the end of XIX century and has 10 lasted up to the present.

Reforestation and mountain renovations are not well documented, but the available data suggest that both of these forms of intervention have been undertaken with effect from the 1920s-1930s. Even the big artificial dams had considerable momentum after the First World War, and later in the 1950s and 1960s. Finally the sediment extraction, 15 corresponded to a period of forty years, from 1950 to 1990 , during which millions of cubic meters of sediment were removed from the main Italian watercourses. These interventions have dramatically altered the regime of sediments, and still, in spite of the situation in recent years has substantially improved, the consequences of so strong interventions are difficult to quantify, monitor and predict. More specifically, in this study,

20 CAESAR regards the application of the model to a particular waterway, the Aniene River. This choice derives from evaluations taking into account the availability of good data, the characteristics of the Aniene basin, the predominance of morphology braided channels within the case study and the morphological evolution that have distinguished the basin in the short and medium term. The rains have an intensity peak in November and a minimum in July. The $60 \%$ of the rains fall during the autumn-winter and only $10 \%$ during the summer. In fact, precipitation values of $1400 \mathrm{~mm}$ per year are registered on Albani Hills, Cimini Hills and Amiata Massif. Extent of precipitation slightly higher has been observed in the Appennine dorsal: $1500 \mathrm{~mm}$ per year on the Sibilini and Tiburtini Hills, $1600 \mathrm{~mm}$ on on Reatini and Simbruini Hills that drains towards the

Aniene. Maximum precipitation of one or more consecutive days is very important in the formation of floods. Hydrographic service data related to 1921-1970 show that the maximum daily rainfall with a duration that goes from one to five consecutive days for all stations ranges between 374 and $534 \mathrm{~mm}$. In conclusion we can say that the con5 ditions for an exceptional state occur when there is a close succession of preparatory precipitations and a determinant precipitation. Preparatory precipitations occur in the two or three months before the determinant precipitation, which occurs only two or three days before the ridge of full.

\section{New functionalities added}

10 Additional functionality has been added with the intent of being able to compare the results obtained with the simulation of flooding and possible map obtained by other software. In particular, it is possible to display a static image that represents the same area examined during the simulation in which you highlight the areas of the flooding theatre. All this has been made possible by adding a specific menu item called "Load

15 Image" in the main bar of the commands as shown in Fig. 5, by mean of which it is possible to reach an initially empty window that allows to select an appropriate image as shown in Fig. 6 (the result of a previous processing, as mentioned above).

With the help of this additional functionality, it is possible to pursue new and very important objectives, as shown in Fig. 7:

1. check the real dynamics of flooding;

2. validate the simulation ended with the image obtained by digital processing;

3. obtain a further estimation of the possible flooding extension. 


\section{Objectives}

This research aims to apply the CAESAR model to a stretch of the Aniene River and to characterize the mapping of the flood boundaries. In addition, a comparison will be made with an existing and well known Open Source Earth Observation System: Next

5 ESA SAR Toolbox (NEST version 4C-1.1). In fact, the principle of using radar for flood mapping is that the intensity of the radar backscattered signal depends on the roughness of the surface it interacts with. Water bodies generally create a very quiet (unless strong winds induce waves) and homogeneous surface. Therefore the incident, side looking, radar pulse will be scattered away from the radar sensor (specular reflection)

10 and the radar image over that area will be black, or very dark due to little return of the radar pulse. The surrounding rough land surface will be much brighter, due to higher return, thereby distinguishing it from the water surface. In order to identify flooded areas from permanent water bodies, an image acquired during the flood needs to be compared with another image acquired when there was no flood. It is necessary to extract

15 both images through the same sensor geometry. This is because the brightness of the radar return depends on the angle and direction of the incident radar pulse.

\section{Flood water extraction from RADARSAT images}

Remote Sensing with Optical sensor depends on sunlight illuminating the Earth in order to obtain useful imagery. Its performance is limited by the presence of clouds, fog, 20 smoke or darkness. However, RADARSAT does not have such limitations. At the heart of RADARSAT there is an advanced radar sensor called Synthetic Aperture Radar (SAR). SAR is a microwave instrument that sends pulsed signals to Earth and processes the received reflected pulses. The SAR technology based on RADARSAT sensors provides its own microwave illumination and thus operates day or night, regardless

25 of weather conditions. Spaceborne and airborne SAR imagery used in flood mapping can be broadly defined as low (about $100 \mathrm{~m}$ ), medium $(10-25 \mathrm{~m})$ and high $(1-2 \mathrm{~m})$

spatial resolutions as in Di Baldassarre et al. (2011). Mapping of water surface using SAR is possible because the SAR backscatter is very low due to the specular reflection as shown in Fig. 8 when the water surface is smooth. As a result, flooded areas appear as dark tones due to the low backscattering response whereas land surface appear

5 as bright tones because the rough soil surface and vegetation produce diffused reflection resulting in a strong backscatter. This tonal variation according to the backscatter response in SAR images can be used to separate water from soil.

The four common steps for a flood mapping area procedure are:

- visual interpretation;

- histogram thresholding;

- active contour;

- image texture variance.

In visual interpretation, flooded area is represented by a visual digitizing method, whereas in histogram thresholding, the optimal gray threshold is used to individuate flooded areas. Active contour model delineates the flood extent based on dynamic curvilinear contours to search the edge image space until it settles upon image region boundaries. In image texture method, tonal changes may be modeled as a gray level function using statistical methods on the image histogram as in Schumann et al. (2009). However, no single method can be seen as the most appropriate for all the images and 20 all methods are not equally good for a particular type of image. An overview of the research methodology is seen in Fig. 9:

the previous flow chart was obtained by the following operations in NEST:

- Creation of the project file and opening the data: both acquired images were used to map the flooding event. One image was taken during the floods, known as the "crisis image" while the second image, known as the "archive image", is covering approximately the same area. 
- View metadata: here is stored the information taken from the metadata files, including the mission, product type, acquisition date and time, track and orbit.

- View geographical coverage of both images: a map will show the footprints of the images calculated from the metadata.

5 - View and crop the images: inspecting both the images, we focus on the extensive dark area of the crisis image. This is the area of flooding and we are interested only in the part of the images where the flood are visible. Cropping the images to include only this area will save much computation time.

- Orthorectification of the images with a DEM.

10 - Create a stack and compare images: in order to compare the two images we stack them together and view them in the same viewer. We then create a 3 color composite image and inspect the changes between the two acquisition times. In order to enhance the differences between the archive and crisis image in one layer we will create an RGB image view. To do this, first we need to ensure that there are 3

15 channels from which an RGB image can be created. This combination will enable us to differentiate between areas that are flooded and permanent water bodies. In areas that are flooded, the red channel will be dark but the green and blue channels will be bright, therefore the pixels should appear bright cyan. A permanent water bodies will be dark in all the channels. All other areas will display a shade of gray as the backscatter intensity should be the same. However, in this case the images are not from the same track, therefore there will be greater differences between the backscattered images even in areas where they should be the same (due to the different viewing angles).

- Save RGB image view as a KMZ file: once the file is saved we can watch it in Google Heart overlaying streets and places names onto the image to see which areas are flooded.

- Calculation of flooded area: we try to quantify the magnitude of the floods. To do this we need to know the number of flooded pixels. The first step is to define thresholds for the pixel values in both images where the flood is present. Good threshold values for flooded areas could be $<800$ for the crisis image and $>900$ for the archive icon. This will mask flooded pixels, without classifying permanent water bodies as flooded areas. To mask only the flooded area and to avoid the edges containing regions not covered by both images, we will utilize the mask only to the function where both images overlap. Knowing the size of the image pixel (see range spacing and azimuth spacing in metadata) and knowing how many pixels are masked as flood, it is possible to calculate the size of the affected area.

\section{Conclusions}

Numerical modeling is undoubtedly a tool with interesting application perspectives in fluvial geomorphological contexts, in particular the so called "Reduced Complexity Models" and among them the "Cellular Model". In the specific context of this research, 15 the CAESAR model, widely described also in Coulthard et al. (1999), is applied to a stretch of the Aniene River with the overall objective to fully characterize the developments of the last $40 \mathrm{yr}$ and then to obtain a quantitative evaluation about its evolutionary trend in the short and medium term. CAESAR, in fact, has been developed mainly to study the geomorphological changes in catchment or riverbed for long time periods (hundreds years). CAESAR is a quantitative model that is currently mainly used for research purposes. The correctness of simulations, however, have been tested essentially from a qualitative point of view. The results obtained, related to erosion/depositions, and to the water head (connected to the channel configuration of lean) are congruent. In conclusion, we can say that CAESAR reproduces realistic 25 results, at least qualitatively, even for studying the effects on the dynamics of riverbed, due to the presence of hydraulic works. It would be interesting, deepening the quantitative aspect; to do this we need to find a consistent amount of data on bathymetry, 
profiles, distribution particle size, liquid and solid flow, spread over a time interval sufficiently large and in different morphological and different beds.

Acknowledgements. I would like to especially thank F. Del Frate and M. loannilli for supporting me and all colleagues in the Earth Observation Laboratory (Department of Civil Engineering

5 and Computer Science, Tor Vergata University) for providing various images for this research.

\section{References}

Beven, K.: Linking parameters across scales: subgrid parameterizations and scale dependent hydrological models, Hydrol. Process., 9, 507-525, 1995. 840

Beven, K. and Kirkby, M.: A physically based, variable contributing area model of basin hydrol-

10 ogy/Un modèle à base physique de zone d'appel variable de l'hydrologie du bassin versant, Hydrolog. Sci. J., 24, 43-69, 1979. 837, 840

Beven, K. and Wood, E. F.: Catchment geomorphology and the dynamics of runoff contributing areas, J. Hydrol., 65, 139-158, 1983. 840

Beven, K., Lamb, R., Quinn, P., Romanowicz, R., and Freer, J.: TOPMODEL, Comput. Model.

15 Watershed Hydrol., edited by: Singh, V. P., Water Resources Publications, Boulder, CO, Chap. 18, 627-668, 1995. 841

Castiglioni, G. B.: Geomorfologia, Utet, Torino, 436 pp., 1982. 834

Coulthard, T., Wiel, M., and Van De, J.: A cellular model of river meadering, Earth Surf. Proc. Land., 31, 123-132, 2006. 837, 841

20 Coulthard, T., Kirkby, M., and Macklin, M. G.: Modelling the Impacts of Holocene Environmental Change in an Upland River Catchment, Using a Cellular Automaton Approach, John Wiley and Sons, Chichester, 1999. 848

Coulthard, T., Kirkby, M., and Macklin, M.: Modelling geomorphic response to environmental change in an upland catchment, Hydrol. Process., 14, 2031-2045, 2000. 837

25 Coulthard, T., Macklin, M., and Kirkby, M.: A cellular model of Holocene upland river basin and alluvial fan evolution, Earth Surf. Proc. Land., 27, 269-288, 2002. 837

Coulthard, T., Hicks, D., and Van De Wiel, M. J.: Cellular modelling of river catchments and reaches: advantages, limitations and prospects, Geomorphology, 90, 192-207, 2007. 837

Coulthard, T., De Rosa, P., and Marchesini, I.: CAESAR: un modello per la simulazione delle dinamiche d'alveo, II Quaternario, 21, 207-214, 2008. 836, 837

De Rosa, P.: Un approccio modellistico per il fenomeno delle occlusioni d'alveo per frane: una modifica al modello CAESAR, Giornale di Geologia Applicata, 8, 277-284, 2008. 842

Di Baldassarre, G., Schumann, G., Brandimarte, L., and Bates, P.: Timely low resolution SAR Imagery to support floodplain modelling: a case study review, Surv. Geophys., 32, 255-269, 2011. 846

Einstein, H. A.: The bed-load function for sediment transportation in open channel flows, 1026, US Department of Agriculture, Washington, D.C., United States, 1950. 837

Formann, E., Habersack, H., and Schober, S.: Morphodynamic river processes and techniques for assessment of channel evolution in Alpine gravel bed rivers, Geomorphology, 90, 340355, 2007. 835

Hoey, T. B. and Ferguson, R.: Numerical simulation of downstream fining by selective transport in gravel bed rivers: model development and illustration, Water Resour. Res., 30, 2251-2260, 1994. 838

Lane, S., Bradbrook, K., Richards, K., Biron, P., and Roy, A.: The application of computa-

15 tional fluid dynamics to natural river channels: three-dimensional versus two-dimensional approaches, Geomorphology, 29, 1-20, 1999. 835

$\mathrm{Li}$, S., Millar, R., and Islam, S.: Modelling gravel transport and morphology for the fraser river gravel reach, british columbia, Geomorphology, 95, 206-222, 2008. 835

Marchetti, M.: Geomorfologia Fluviale, Pitagora edn., Bologna, 2000. 834

20 Montoya Cardona, M. M.: Analisi dinamica-morfologica dei corsi d'acqua pseudo meandriformi mediante modelli a fondo mobile, Tesi di Dottorato in Idronomia Ambientale, Università degli studi di Padova, Padova, 2008. 835

Murray, A. B. and Paola, C.: A cellular model of braided rivers, Nature, 371, 54-57, 1994. 836

Murray, A. B. and Paola, C.: Properties of a cellular braided-stream model, Earth Surf. Proc. Land., 22, 1001-1025, 1997. 836

Murray, A. B. and Paola, C.: Modelling the effect of vegetation on channel pattern in bedload rivers, Earth Surf. Proc. Land., 28, 131-143, 2003. 836

Newson, M. and Sear, D.: River conservation, river dynamics, river maintenance: contradictions, in: Conserving our Landscape Joint Nature Conservancy, edited by: White, S., Green,

$30 \quad$ J., and Macklin, M. G., Peterborough, UK, 139-146, 1993. 834

Nicholas, A. P.: Cellular modelling in fluvial geomorphology, Earth Surf. Proc. Land., 30, 645649, 2005. 835 
Quinn, J. M., Coleman, R. J., Macmillan, S., and Barraclough, D. R.: The 1995 revision of the joint US/UK geomagnetic field models, II: Main field, J. Geomagn. Geoelectr., 49, 245-261, 1997. 840

Schumann, G., Bates, P. D., Horritt, M. S., Matgen, P., and Pappenberger, F.: Progress in inte-

5 gration of remote sensing - derived flood extent and stage data and hydraulic models, Rev. Geophys., 47, RG4001, doi:10.1029/2008RG000274, 2009. 846

Surian, N., Ziliani, L., Cibien, L., Cisotto, A., and Baruffi, F.: Variazioni morfologiche degli alvei dei principali corsi d'acqua veneto-friulani negli ultimi 200 anni, II Quaternario, 21, 279-290, 2008. 843

10 Surian, N., Rinaldi, M., Pellegrini, L., Audisio, C., Maraga, F., Teruggi, L., Turitto, O., and Ziliani, L.: Channel adjustments in northern and central Italy over the last 200 years, Geol. S. Am. S., 451, 83-95, 2009a. 843

Surian, N., Ziliani, L., Comiti, F., Lenzi, M. A., and Mao, L.: Channel adjustments and alteration of sediment fluxes in gravel-bed rivers of North-Eastern Italy: potentials and limitations for channel recovery, River Res. Appl., 25, 551-567, 2009b. 843

Van De Wiel, M. J., Coulthard, T. J., Macklin, M. G., and Lewin, J.: Embedding reach-scale fluvial dynamics within the CAESAR cellular automaton landscape evolution model, Geomorphology, 90, 283-301, 2007. 837

Wilcock, P. R. and Crowe, J. C.: Surface-based transport model for mixed-size sediment, J. Hydraul. Eng., 129, 120-128, 2003. 837, 838

Wolfram, S.: Universality and complexity in cellular automata, Physica D, 10, 1-35, 1984. 836

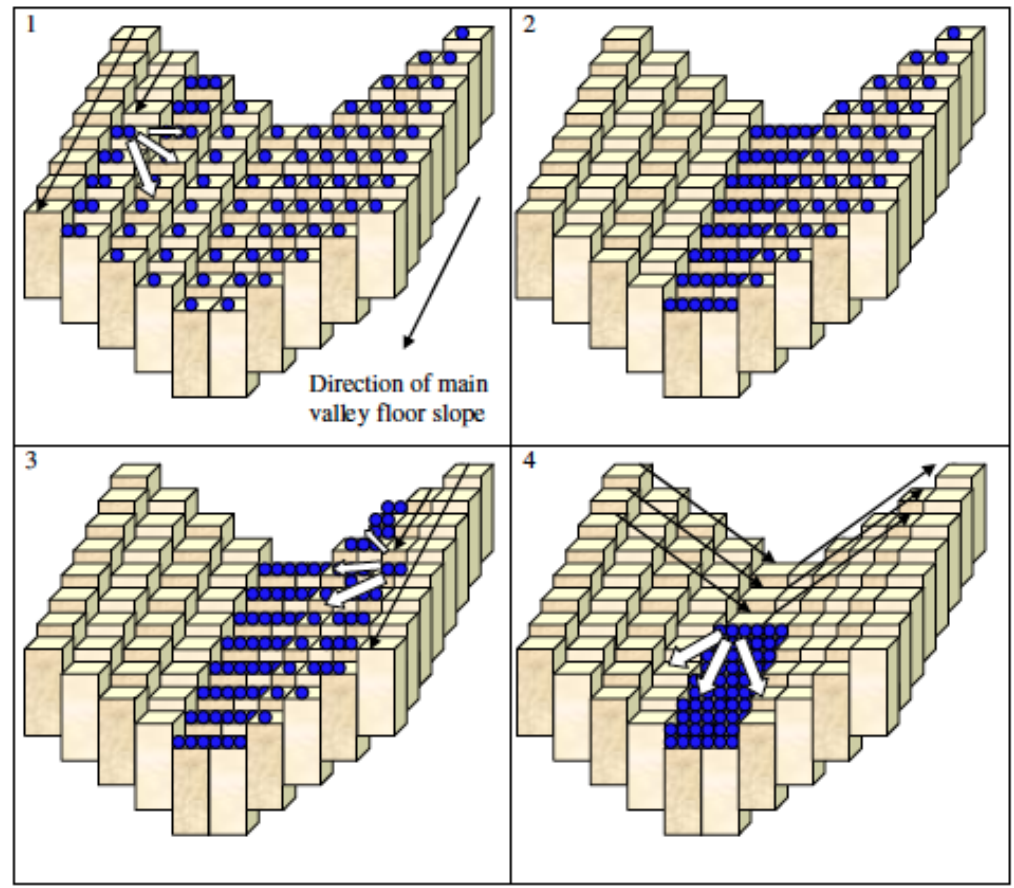

Fig. 1. Schematic diagram of the CAESAR scanning flow routing algorithm. 


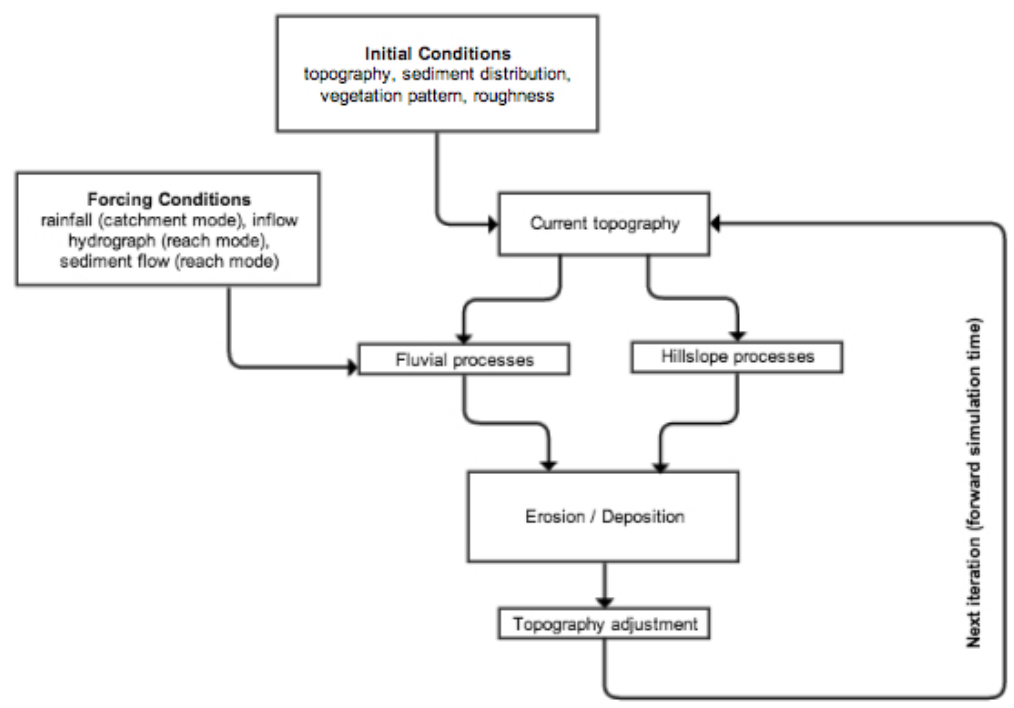

Fig. 2. Schematic of CAESAR's operation.

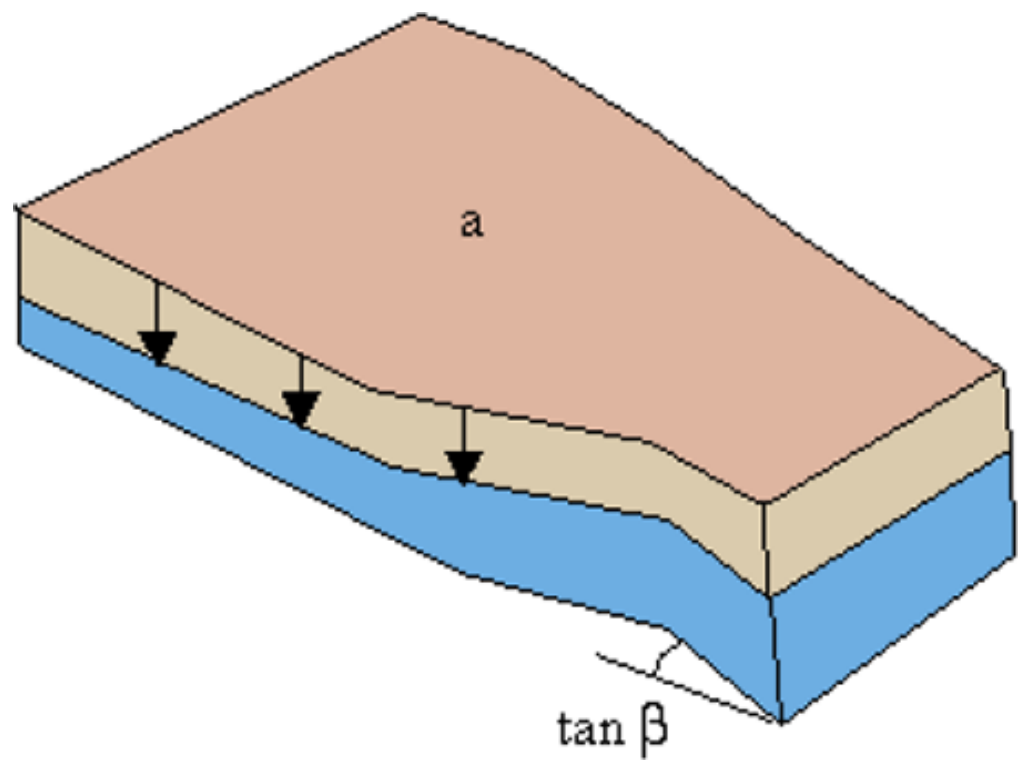

Fig. 3. Determination of the Kirkby's topographic index. 


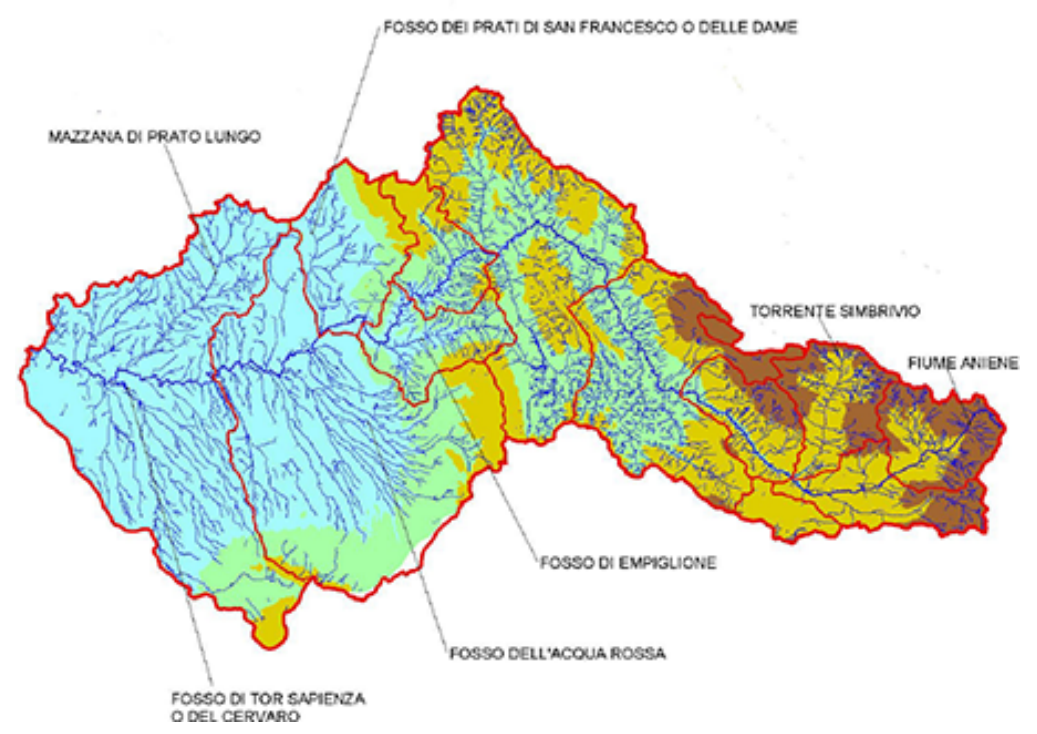

Fig. 4. Hydrographs and altimetry for Aniene River.

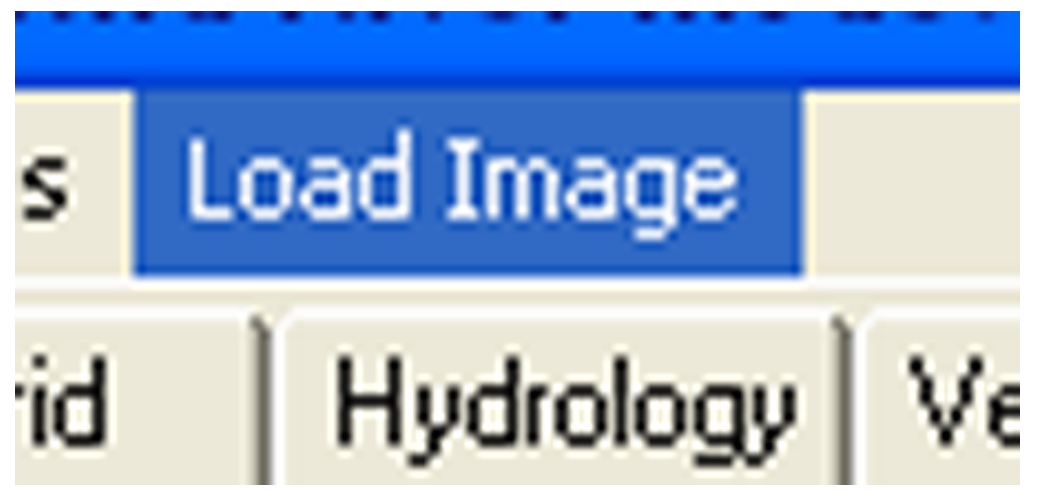

Fig. 5. Main menu path. 


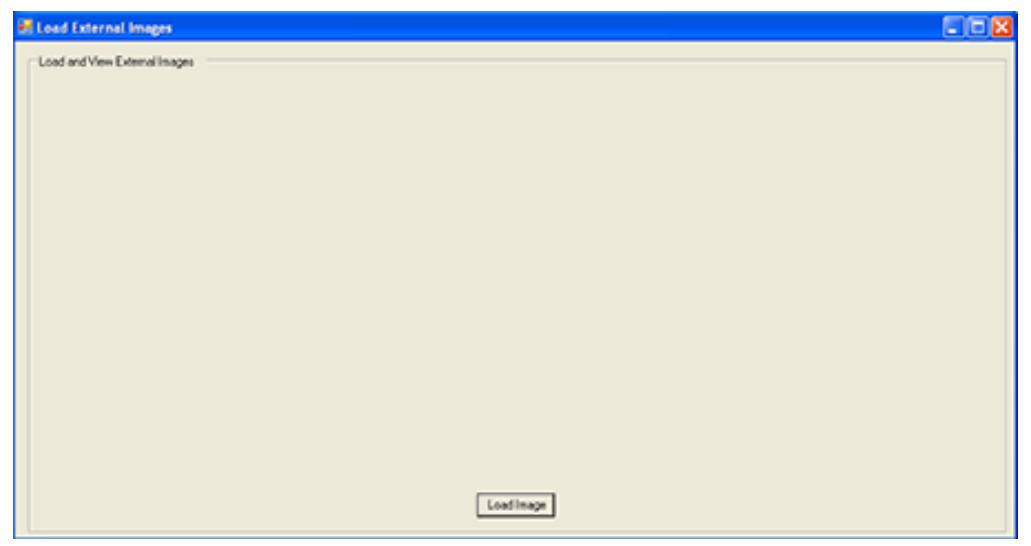

Fig. 6. Load new image in an empty window.

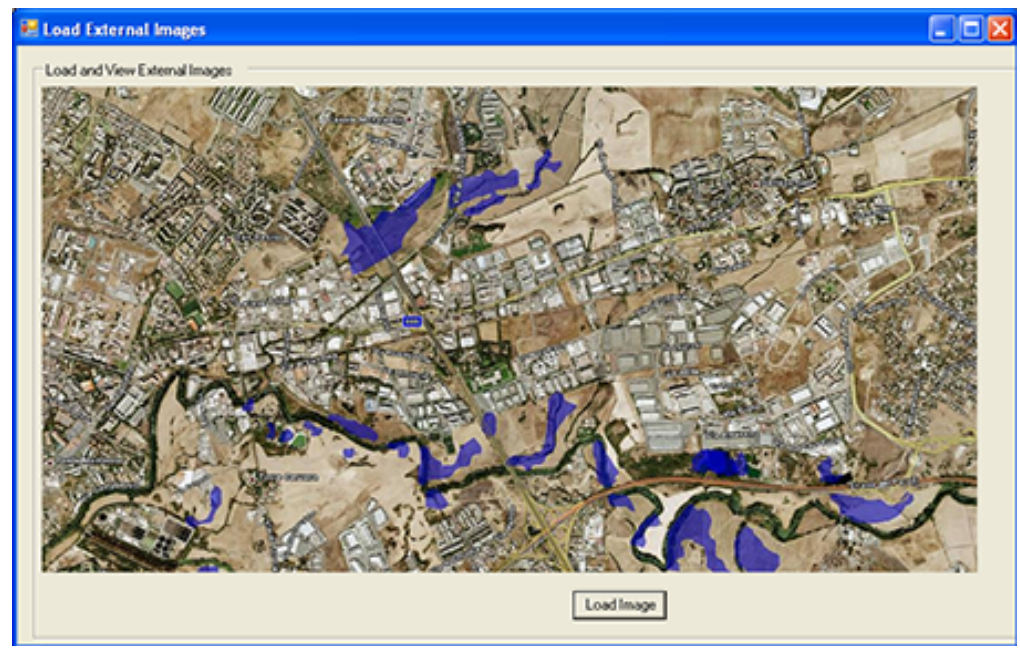

Fig. 7. Sample imported image. 

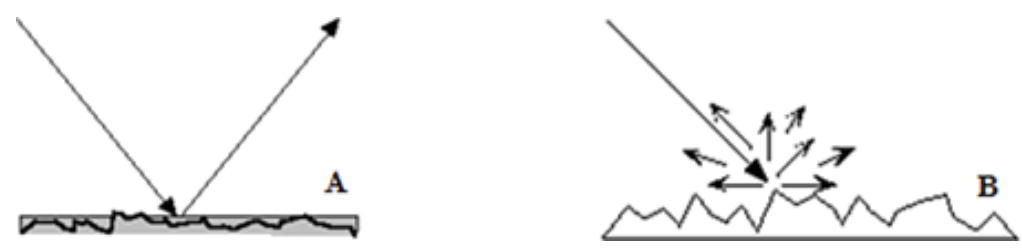

Fig. 8. (A) Specular reflection from flooded areas; (B) diffuse reflection from non-flooded area.

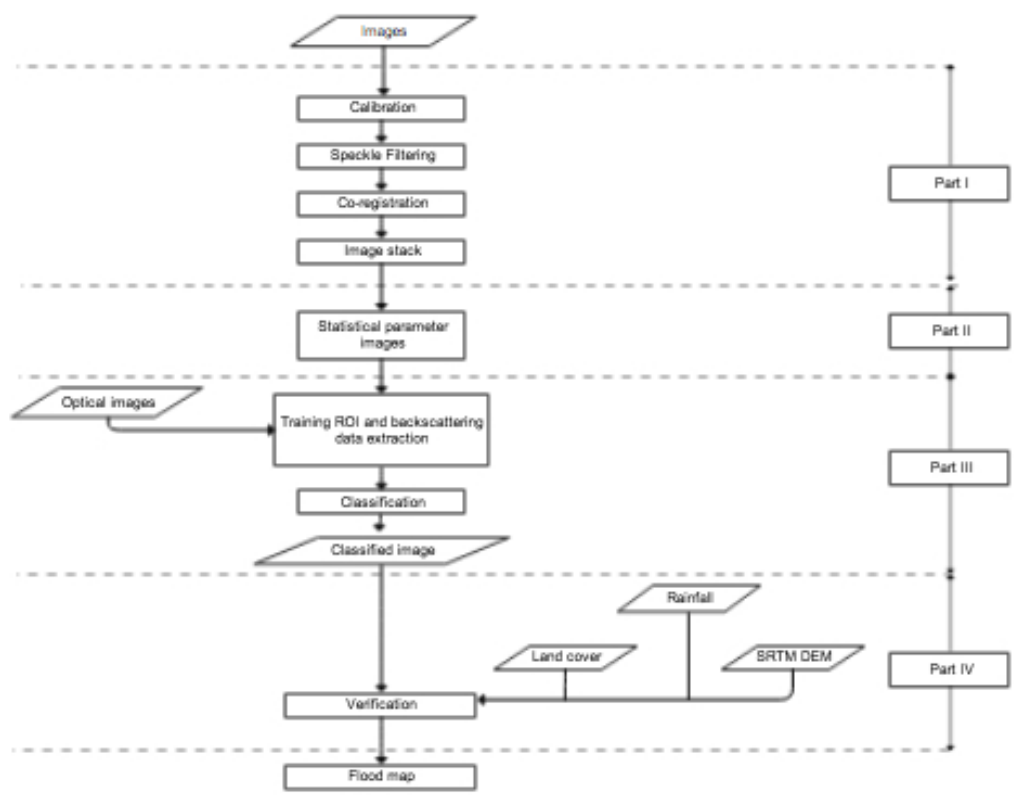

Fig. 9. Flow chart of the flooded area extraction. 